
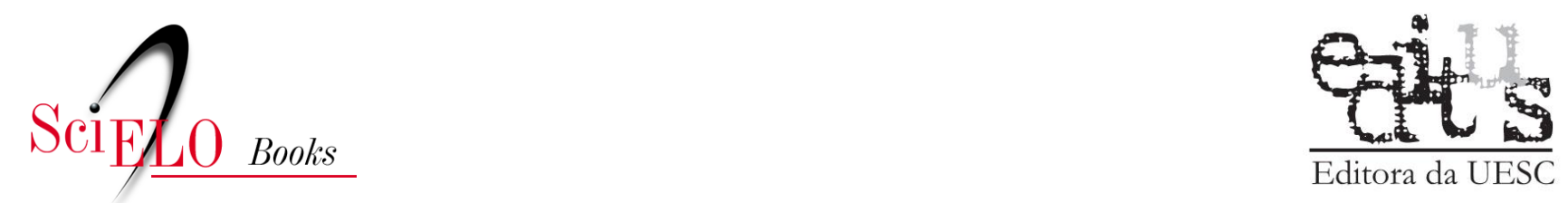

\title{
Imagens do homoerotismo na ficção baiana
}

\author{
Paulo César Souza García
}

\section{SciELO Books / SciELO Livros / SciELO Libros}

GARCÍA, PCS. Imagens do homoerotismo na ficção baiana. In: MITIDIERI, AL., and CAMARGO, FP., orgs. Literatura, homoerotismo e expressões homoculturais [online]. Ilhéus, BA: Editus, 2015, pp. 217-239. ISBN 978-85-7455-442-6. Available from SciELO Books <http://books.scielo.org>.

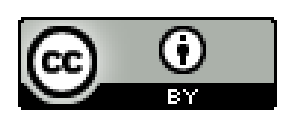

All the contents of this work, except where otherwise noted, is licensed under a Creative Commons Attribution 4.0 International license.

Todo o conteúdo deste trabalho, exceto quando houver ressalva, é publicado sob a licença Creative Commons Atribição 4.0.

Todo el contenido de esta obra, excepto donde se indique lo contrario, está bajo licencia de la licencia Creative Commons Reconocimento 4.0. 


\title{
IMAGENS DO HOMOEROTISMO NA FICÇÃO BAIANA
}

\author{
Paulo César Souza García ${ }^{1}$
}

A representação do homoerotismo na ficção contemporânea tem dado amostras de enunciados sobre os desejos sexuais excludentes, sobre os corpos que pesam (BUTLER, 2000) e sobre as bases que focalizam o subalterno. Um estudo de Flávio Camargo, a respeito do homoerotismo na obra de Caio Fernando Abreu, afirma que a produção literária do autor é referência ao preconceito, à discriminação e à violência homofóbica:

[...] simplesmente porque ousaram expressar e expor ao público seus desejos, sua identidade, sua sexualidade. De tal forma que as experiências homoafetivas e ou homoeróticas, assim como os ritos de iniciação sexual e de passagem são balizadas, muitas vezes, pela presença constante da violência (CAMARGO, 2011, p. 241).

1 Doutor em Teoria Literária (UFSC). Professor da Graduação em Letras e da Pós-Graduação em Crítica Cultural da Universidade do Estado da Bahia - DEDC II (UNEB).

E-mail: 〈p.garcia@terra.com.br〉. 
O exemplo da análise oferecida por Camargo em relação a Caio $\mathrm{F}$. é sintomático de leituras que manifestam os questionamentos sobre as identidades, uma marca que a literatura moderna e da contemporaneidade tem proporcionado aos leitores mais ávidos pelas pesquisas sobre gênero e diversidade sexual. Se em Caio F., a experiência homoerótica ganha corpus de enunciação, ainda mais presente com o sentido da ausência e carência de afetividade do sujeito, como pensa Camargo (2011), em muitas outras obras da literatura brasileira esta inquietação em falar de si não somente delineia e ilustra o traço da identidade homossexual, como se reporta ao poder falar sobre.

As narrativas de Caio F. anunciam os imperativos e os flertes homoeróticos, que são perceptiveis a olho nu e na artimanha da sociabilidade entre homens. Algumas narrativas, a exemplo do conto "Aqueles dois", são porta-vozes de relatos que articulam o desejo gay através do toque do corpo, do olhar, das sensações, de sentir os gostos e prazeres anunciados. No relato "Aqueles dois", o envolvimento homoerótico sai do anonimato, dando preferência ao amor e não apenas ao sexo, mesmo que, como pondera Flávio Camargo, Caio F. assegure "a onipotência da solidão, por um sentimento de falta, de carência afetivosexual, por um vazio existencial e pela angústia" (CAMARGO, 2011, p. 242).

A partir da imagem dos desencontros afetivos situados na metrópole moderna, nota-se 
mais ainda o emaranhado de existências excêntricas demarcadas nas zonas de desvios, sobressaindo a carência, a solidão, o medo de amar. Como Caio F., João Gilberto Noll apreende os desfalques da identidade masculina na onda da vida líquida (BAUMAN, 2004), nos desvãos de um tempo atravessado por evasões, por fugas, pelos entrecruzamentos de relações individuais muitas vezes nada assépticas. Como crítico de uma realidade retratada, Noll se vê imerso numa linguagem que não deve ser seguida pela estrutura binária, já que as histórias apresentam eixos de sentidos nada lineares e são mais descentralizadas da unidade do signo. Os enredos se mostram no plano do rotativo, com descrições avessas a lugares fixos e é nesses entrecortes discursivos que o estilo do narrar do autor se apresenta sobressaltado, destacando a inserção de personagens fora-de-lugar.

Talvez, frente a isso, a escrita de Noll seja girada pela consequência de perceber o real nutrido por dados reguladores que contaminam a esfera da subjetividade. Assim, suscitam as relações afetivas entre homens, que temem locar a chama unificadora do amor, porque o ato de amar é visto pelos personagens masculinos como um ato de integração, de ligação a um ser estranho. Sendo assim, sobressaem o vazio da existência e a incapacidade de o homem lidar com o sentimento de perda e de desapego. Algumas dessas motivações existenciais giram em torno da aproximação amorosa e sexual que configura o amor 
líquido, podendo estar atrelado, aí também, o dispositivo imposto a cada pessoa que se submete ao poder totalitário da vida moderna, ao consumo e à necessidade de gozar a todo custo (BAUMAN, 2004).

O manifesto de Bauman pode dar mostra à interpelação do sentido imposto, à revisão do centro dos conceitos assépticos, pondo em ação os reflexos sobre quem fala e como fala. Se as faces dos sujeitos da literatura são desenhadas não para reproduzir o real, mas para envergar a linguagem que reflita as assimetrias, os desarranjos, a desautomatização ordinária da realidade, assim visto, o ato de diferir dos narradores ficcionais é proposital, uma vez que a escrita literária flerta com o lado de fora, com os instantes em que a linguagem difere de si mesma, ou seja, é a própria diferença da língua se desdobrando para recondicionar o sentido da realidade. Dessa forma, as singularidades das escritas do literário acusam a alternativa de novas outras formas de expor a si, daqueles que estão fora-de-lugar ou no entre-lugar (BHABHA, 2001).

Ao apresentar a parte introdutória e propositiva sobre a literatura de Caio F. e de Noll sob o aspecto do homoerotismo, pretendo dar enfoque à literatura baiana da contemporaneidade. A obra da escritora baiana Állex Leilla ${ }^{2}$ revela imagens propositadamente deslocadas com o representável, que dá vistas

2 Urbanos (1996), o sol que a chuva apagou (2009), Primavera nos ossos (2010) são obras publicadas pela autora na geração atual da literatura baiana. 
a instaurar uma força-motriz que enaltece o poder falar de si a serviço e à ordem do consumo do corpo, para reaver a capacidade de desafiar o medo social diante das entregas do desejo homoerótico. Situo o romance Henrique (2001), cujos sentimentos das personagens são enaltecidos, à mercê do fracasso e da culpa, da cumplicidade e da perseguição, dados os tabus da vida ordinária ligados à homossexualidade pecaminosa e aos estorvos familiares. O amor homoerótico é focalizado sob um discurso anti-higiênico para os padrões morais, porque nos diz muito da relação de fórum edipiano, quando expressa o contato homoafetivo entre pai e filho e entre irmãos. A literatura de Állex Leilla descreve a discrepância do patriarcalismo e desnuda o sistema familiar regrado e conservador.

A história de Henrique parte da ação do protagonista, que dá nome ao romance e se desdobra em algumas micro-histórias, como o amor que Henrique nutre por Victor, melhor amigo de infância. Um sentimento amoroso que atravessa a adolescência e vai até a maturidade, mas passado pelos percalços da dúvida, do medo, dos questionamentos a respeito de sua orientação sexual, consequência dos rígidos padrões sociais e familiares. O narrador - protagonista interage com as diferentes experiências que são mediadas pela focalização de outros autores da literatura situados no texto, remetendo ao corpus discursivo, diálogos que se contrapõem ao heterossexismo e às declarações avessas à heteronormatividade. 
No enredo do romance, são pautados a repressão, os paradigmas heterossexistas, o arbitrio, o autoritarismo de convivio familiar, a quebra de conceitos heteronormativos, a imagem do pai do protagonista que se desencaixa dos elos do sistema patriarcalista e aposta na amizade intensa com o filho, esta expressa pela convivência mais livre entre os dois. No entanto, o amor de Henrique pelo pai vai além do espiritual, concentrando-se na esfera sexual. O corpo fala mais em razão do desejo sexual, ressurgindo a tensão de base edipiana. Mais do que uma relação transgressiva, Henrique se desvela, mostra a si mesmo no plano do desejo mal-dito, no poder de enunciar a si no espaço da exceção, ou melhor, buscar a identidade para além da limpeza dos relacionamentos sagrados e normativos, ao consagrar a presença do pai:

A palavra homem para mim estava diretamente relacionada à imagem do meu pai. Mas ele sempre foi ligado a todas as formas de vida que há na Terra, sem predileção especial por nenhuma e convivendo naturalmente com todas, como eu procuro até hoje viver, como sempre procurei e nunca pude. Há formas de vida que desentendo completamente, há outras que odeio... [...] Meu pai, uma tragada lenta e profunda, os glandíolos que ele me trouxe ontem ainda vivos, as pausas que seguem sozinhas, independentes de um querer definido. Meu amor. Depois do amor, pode-se furar mesmo os olhos. É coisa mais certa de se fazer (LEILLA, 2001, p. 141-144). 
Luís também confessa ao filho a relação incestuosa com o irmão. Para ele, um relato libertador, quando condiciona uma relação aberta e amorosa para o filho. A quebra dos conceitos arraigados heteronormativos sobressai com a consideração de Luís, que não enxerga nenhum problema em amar e transar com o irmão. Os irmãos Leão e Luís sentem desejo sexual um pelo outro desde criança, desejo despertado pela atração física, criado sem traumas. Parece que a trama espreita o imaginário social com o ato do confessionário, sendo este adentrado na enunciação de descobertas, de desmascaramentos, de rever os fantasmas que eles não se veem e de se perceberem como os excluídos. A escrita transita livremente por lugares nada convencionais e nada confortantes para o seio familiar de base fundamentalista e patriarcal. Até a descoberta do pai de Luís e Leão, que exalta a condição sagrada e pecaminosa do sexo homossexual entre os filhos. Um retrato discursivo que volta ao plano do mesmo, que retorna para a imagem e para os dispositivos da repressão:

Meu pai me contou uma vez a sua história, ou parte dela, talvez. Quando completara cinco anos e o tio Leão tinha oito, a mãe os pegara nus. Cinturas coladas, fundindo-se numa só. Foi um escândalo. Ah! Ele adorava o Leão, cresceram assim, unidos. Dormiam abraçados sempre que podiam. Acariciando-se, mordendo-se um ao outro. Faziam tudo juntos. E apanhavam juntos também. Os pais 
estranhavam tanta proximidade. - E trepávamos sempre. Muito além do que podiamos. Não tínhamos outros amores. Éramos um pro outro. Até os meus 17 anos, ninguém sabia que a gente se amava. A-t-é-q-u-e-u-m-di-a... - Enfim, descoberto tudo, ficou claro que não era só uma brincadeira de criança, pois, mesmo depois daquele flagra (pelo qual fomos seriamente punidos, é bom que se lembre), nós nunca deixamos de nos amar. Então vieram mais porradas, todas as repressões, todas as pieguices, todos os chavões dramáticos (LEILLA, 2001, p. 63-64).

Se Luís abala o pensamento dicotômico normal versus anormal ao relatar para o filho o amor homossexual com o irmão e depois com o próprio filho, ele não somente mostra ser livre da imposição aos sentimentos de vínculos familiares, como enuncia criticamente os valores relacionais heterossexistas e heteronormativos da cultura ocidental postos em xeque, como também critica a estrutura dos modelos da cultura judaico-cristã, fazendo ruir o pensamento fundado na versão homem versus mulher. A válvula de escape se dirige para a negação da fórmula do amor heterocentrado limpo, desautorizando os elos comunais religiosos. Se existe uma "violência" ao corpo anunciada entre pai e filho e entre irmãos, ela simboliza a desvinculação dos rótulos e de nomeações instituídas, pois aí a reflexividade do corpo não abdica de se vincular aos novos perfis dos relacionamentos, tendo em vista os 
atos homoeróticos e as identidades construídas por novos rumos e rotas.

Pode o sujeito gay ocupar este lugar de fala? As histórias que nos são narradas em Henrique convidam a reposicionar o amor gay na errância sexual, abordado para reproduzir o controle dos corpos, a destituí-lo, e para repensar as perseguições dos que ousam amar o outro do mesmo sexo. Os relacionamentos homoeróticos, traçados no livro Henrique, causam estranhamentos por ter em mente "a perpetuação do interdito sobre a sexualidade, e por silenciar ou punir tudo e todos os que não são contemplados pela moralidade burguesa ou que nela não se enquadram", como bem define Emerson Inácio (2010, p. 113). Aqui, o relato do amor entre pai e filho, e entre irmãos, pode ser representável no espaço ficcional, visando ao lugar da subalternidade para exercitar interpretá-lo na repetição dos contextos históricos e culturais, como para visualizá-lo e analisá-lo diante do legítimo poder social versus as identidades e as categorias de gênero e de orientação sexual.

A experiência do infame amor homoerótico no romance pode ser um percurso de leitura que tenha em mira a forma de interpretar $\mathrm{o}$ devir-sujeito, de situá-lo na movência, na contramão e na contradição de sentidos arraigados pelo centro hegemônico. Se importa para a literatura de temática homoerótica a desterritorialização de lugares fixos e reterritorializar percursos mais fluentes para saber de si e do outro, as escritas se deparam com a minoria que não se lê, não se vê, não se escreve. 
Destaco o livro de contos do escritor brasiliense Lima Trindade ${ }^{3}$, Corações blues e serpentinas, cujas histórias enredam a imagem de homens refletida nos perfis de personagens brancos, de classe média, situados em passados sombrios, que são tenebrosos ao vivenciar o amor gay. Aí, o imaginário se presentifica numa carga de preconceitos, ao lidar com o desejo homoerótico vasculhado na espreita. $\mathrm{O}$ olhar do personagem é sempre penetrante, enviesado. A paquera ao parceiro desconhecido reproduz as condições históricas de marginalização e clandestinidade dos contatos entre homens, como se o fato de as expectativas de entrega ao corpo do outro girassem em torno do apaziguamento e do sofrimento do amor.

Assim, o universo da escrita de Lima Trindade investe em personagens que buscam o lado masculino homossociável e, ao mesmo tempo, são acobertados pelos códigos morais, celebrados por um tom de lirismo, deixando evocar o enaltecimento do belo e a exaltação de si no confessionário da enunciação. No conto "A primeira vez", a personagem reverbera o homem, exaltando a beleza do masculino e o problema de afirmar a orientação e o desejo sexuais:

[...] lembro que tinha um espelho na sala e eu não olhava diretamente para ele, mas para o espelho, porque assim

30 escritor nasceu em Brasília, mas adota a Bahia para viver. Publicou Supermercado da solidão (2005), Todo o sol mais o espírito santo (2005). 
ninguém descobriria o que comigo se passava: que eu estava apaixonado e com medo que alguém pudesse desconfiar de meu amor que naquela hora não era todo consciente, era meio misturado à bebedeira. Sim, era a bebedeira que fazia isso com a gente, confundia o gosto e a noção de beleza, porque um homem não pode achar bonito outro homem, ainda mais se a beleza tiver uma aura de sensualidade (LIMA TRINDADE, 2007, p. 89).

A narrativa mostra a identificação de práticas repressoras, quando a beleza do homem é alvejada e revisitada por meio da metáfora do espelho. Do lado de fora da realidade, reflete o ser discriminado por revelar o desejo abreviado e, por sua vez, a referência ao gay é sempre visada pela condição de subalternidade. Dito isto, o olhar reescreve as polaridades que envolvem a identidade sexual, levadas pela discrição do personagem e pela inserção do olhar de fora que estigmatiza, projeta-o como desviado, indecente e pervertido. A narrativa preserva nuanças que colaboram para pensar o personagem ocupando o espaço da exclusão diante do gesto de domesticação de si, também ligado às estruturas débeis do sistema sociocultural, movidas pelas significações ortodoxas e hierarquias estabelecidas.

Em "Amor inconsútil”, outro conto do autor da mesma coletânea de Corações blues $e$ serpentinas, a narrativa promete dissolver o instituído e os conceitos transversais do amor, compreendendo a coexistência do sentimento 
amoroso entre dois homens. A narrativa apresenta o dilema entre André e Antônio mostrado no ápice das cobranças. "- Você me ama. - O que é amar? - É me possuir como se eu fosse um cãozinho, protegendo e alimentando... - Então, não te amo" (LIMA TRINDADE, 2007, p. 45).

Para Enrique Rojas, "é preciso construir uma nova pedagogia do amor, partindo de nós próprios e não do prazer sexual colocado à frente do amor" (ROJAS, 1996, p. 50). O amor de Antônio beira à insegurança, o temor da perda, sinalizando, em primeiro plano, a posse do corpo de André. Na tríade amorosa, surge Lúcio na vida de André, que o faz rever a postura e o significado da convivência com outro homem, numa flagrante concepção de que o relacionamento amoroso homossexual é prescrito e semelhante aos padrões heterossexistas, que aprisiona, sufoca, corroendo a relação, ou é instrumento do corpo a serviço de saciar a sede sexual:

Lúcio nada cobrava, não pedia amor nem gestos de carinho. Quando falava, eram sempre a respeito de coisas não refletidas, condicionadas. Você viu o último capitulo da novela das oito? Conhece a piada do...? estou a fim de comprar um carro novo (LIMA TRINDADE, 2007, p. 45, grifos do autor).

A experiência de quem fala no contexto civilizado urbano, em que se aborda o vínculo com o sexual homoafetivo, demarca o limite do 
eu e do outro, ainda mais quando surge "no modo como as transformações do capitalismo são correlatas de mudanças nos modos de relacionamento afetivo instituído no corpo social" (CUNHA, 2009, p. 103). Para Giddens (1993), a experiência segregada, de acordo com o pensamento positivista, refere-se ao processo de ocultação que separa a rotina da vida ordinária dos envolvimentos vários do social. Portanto o envolvimento homoerótico de André por Antônio pode traduzir o medo de se tornar dependente de outra pessoa e, como argumenta Sennett (2003, p. 167), "é uma falta de confiança nela; em vez disso, prevalecem nossas defesas". A defesa de não se envolver amorosamente e o máximo é se engajar no corpo, na zona fronteiriça do prazer, foco da elocução da narrativa:

André não queria mais ilusões. Queria a deriva. E mais, existe o medo de envelhecer, de perder a vitalidade do corpo, de ser negado como idoso e gay, de modo a ser indagado por Antônio: - Não sou mais um garoto para você? - Por que pergunta? Eu é que devo ser velho demais para você. - Mas não era quando eu tinha dezessete e você cinquenta, André. Ou, pelo menos, você não parecia pensar assim - disse num tom triste, porém calmo. - Eu te amo mais que tudo André! O meu amor é um amor sem fronteiras e sem remendos. O que é sexo perto disso? Depois, ficaram mudos por muito tempo. Até que André se vestiu e, sem se despedir, foi ao encontro de Lúcio. Não voltou para pegar os livros (LIMA TRINDADE, 2007, p. 46-47). 
Para Antônio, resta comungar a ideia da pedagogia do amor, como afirma Rojas. Para André, o amor deve ser vivenciado para além do domesticado, efetivamente fugaz ou, melhor dizendo, atravessado pela livre expressão de si. André contextualiza os gestos de deriva sexual, mais sexo, menos amor, reforçando o tecido dos textos que representam os solitários determinados a encarar a individualidade com suas mutações rápidas e ininterruptas típicas da imagem fugaz da realidade social (SIMMEL, 1967), pois, aí, mostra-se o semblante do anônimo atraído mais na onda da "vida liquida", problematizada por Bauman, ou seja, sujeitos fadados a condições de incertezas constantes. Assim, também, as relações amorosas homoeróticas são pautadas na versão perniciosa de competição, de interações, de exclusões, vidas mais liquidas, menos assépticas, se comparadas com os padrões heterossexistas.

Em "Eu James Gandolfini (ou Jukebox)", conto publicado no livro Geração zero zero: fricções em rede, organizado por Nelson de Oliveira, o protagonista da narrativa se vê na pele do personagem do cinema, interpretado por James Gandolfini, um gordo que assume sua identidade sexual. Como um flâneur, o protagonista transita no basfond do centro de São Paulo, no bar "Caneca de Prata", local em que os ursos, assim denominados os gays peludos e gordos, se encontram e paqueram, jogando com as piscadelas de olhares que atraem aqueles que se distanciam de corpos moldados e sarados. 
Em estudo sobre a manifestação do corpo, Wilton García (2001, p. 89) afirma que

[...] a erótica aparece na expectativa do trânsito. Como agente intermediário do corpo, o Eros trata de adequar as condições possiveis para manter a energia pulsante da vida. [Quer dizer que,] dentro dessa circulação apresentada, o objetivo principal é 'estar em atividade', não importa a chegada ou partida, mas sim o deslocamento num movimento entremeio. Portanto, a erótica está no intervalo (GARCÍA, 2001, p. 89).

Dentro desse contexto, o personagem parece seguir o exemplo salvaguardado na aversão aos corpos sarados e projetados como referencial para atrair o olhar do outro, com todos os músculos tonificados, com todos os corpos másculos, sarados e "higienizados":

[...], penso, agora, aqui, sentado junto ao balcão - ainda mais que não chovia havia um bom tempo e eu não costumava avançar pelas ruas com uma garrafa de conhaque debaixo do braço, oprimido pelo intuito imperioso de encontrar alguém que me amasse como eu era - grande, gordo e calvo; olhos bovinos, mas dentes brancos e perfeitos -, porque eu me cuidava de verdade, gostava de mim, gostava tanto que me mimava às vezes e ouvia Charles Mingus com a paixão de quem faz tudo isso sem comer morangos mofados (LIMA TRINDADE, 2011, p. 400-401). 
Na contramão do corpo barbie, o protagonista apresenta a clave urso como parte de um terriório em que o desejo é confinado. Aposta na brutal evidência do excesso do corpo e, no reflexo do outro, não se deixa vencer pela autodeterminação homoerótica recortada no décor do físico.

Cães - melhor diria, ursos? - zelosos, protegendo a fachada do bar. Todos eles lembram um pai perdido, um pai que, por um desentendimento qualquer, juntou as tralhas e ganhou $\mathrm{o}$ mundo (LIMA TRINDADE, 2011, p. 401).

Assim, a metáfora do urso é pertinente para destacar outros códigos de vivência homoerótica, ganhando face e visibilidade.

Ao construir a imagem do urso, o narrador busca se autorrefletir com as caricaturas adotadas e o meio de atrelar, à estrutura social, a identidade gay pelo formato único do corpo. O protagonista não se autopune por ser gordo e peludo, mas internaliza seus signos na linha de discurso que os discriminalizam, desenhando uma nova relação identitária com a cultura gay. Narrador e personagem da história preenchem com a imagem de si as circunstâncias em que se deparam com a matéria de vida reinventada. O próprio personagem se constitui como sujeito de discurso, contracenando com os aspectos mais próximos de si, posto que escreve a partir do olhar que capta as imagens homoamorosas: 
O baixinho ao meu lado possui um olhar tristíssimo, apesar do sorriso meigo e dos gestos seguros ao levar a caneca de bebida à boca, molhando a barba de espuma. Ele não parece meu pai. Quero dizer, todos parecem pais quando são ternos e acolhedores. Que se fodam Freud e seus complexos. Somos eu e ele. Dois caras. Homens. Que se amam. E o baixinho é bem bonito. O incrivel neste bar é justamente isso, nele você pode ser e querer o diferente. Dar-se ao luxo até de ser malencólico numa noite seca de outono. E romântico (LIMA TRINDADE, 2011, p. 402-403).

Sob certa rubrica autobiográfica, a narrativa James Gandolfini, pretensão do autor implicito e personagem da história, trata de demarcar o momento em que a verdade das subjetividades ampara um elo discursivo: a forma de se subjetivar em experiências homoamorosas. "Fumo meu cigarro. Sou James Gandolfini e posso me transformar em Jack Radcliffe de um instante para o outro, se desejar. Eu James e Jack" (LIMA TRINDADE, 2011, p. 403). O desdobramento de si atenta para o modo como o personagem relata a experiência do movimento do seu corpo e, enquanto o faz, cria os signos que representam a si mesmo, uma imagem de si no tempo exato em que segue com o olhar o homem baixinho que deseja conhecer:

De qualquer modo, viro-me em direção ao homem árabe. Ele pode se chamar Kalil, Lázaro, Marcelo. Virome. Viro minha cabeça e meu corpo, 
esbarrando levemente o joelho em sua cintura, projetando minha vista para além dele, para fora do Caneca de Prata. Ele não se move, o rosto voltado para o maldito espelho que reflete outro espelho na parede atrás de nós. Enquadrinha-me. Ri de mim. Posso jurar, mesmo sem ver. Finjo esperar alguém (LIMA TRINDADE, 2011, p. 403).

A evocação realça o ineditismo do olhar em detalhes, conduzindo passo a passo a presa a quem deseja enlaçar. O sujeito protagonista de seu próprio relato fala de si mesmo na própria ação narrada. Contudo, o que vem à tona é o imaginário do personagem que aponta para uma subjetividade em processo que diz e coloca a imagem a serviço do desejo:

'Oi, eu me chamo James Gandolfini'. Reconheço a voz de Bono e balanço a cabeça no ritmo do som. Ele espera um sinal, uma palavra, um gesto meu. Está de frente para mim. Esperando. Eu despenco. Adio. Faço-me prisioneiro. O pior: capaz de perceber toda a doçura existente nesse homem, sentir seu perfume mesclado ao sabor tenro de um bom charuto. Anoitece em mim. Estamos eu e o árabe juntos. Recordo a cena de um filme, uma página lida em solidão (LIMA TRINDADE, 2011, p. 403-404).

Quer dizer, o personagem se vê, se constrói na ânsia do narrar. Porém, falta palavra. 
E se excede na ação que se reflete no próprio ato de narrar. Por esse feito, James é o ator que, sem palavras, protagoniza sua história, e se vê através dela, dos espelhos que produzem a imagem de si e do outro que mira, mas se percebe no esgotamento da experiência:

O veneno e a palidez de um jovem casal. Vivo neles e eles em mim. Lanço meu apelo, meu pedido de socorro, cego sobre os arranha-céus. Se eu falasse, talvez seguíssemos por um caminho conhecido, seguro. Nós brindariamos sorridentes à madrugada. Nossas palavras se emendariam, completando-nos. Eu mostraria a ele minha casa, as fotos premiadas numa exposição, minha banheira. E, antes do amor, eu secaria suas costas com toalhas felpudas, exibindo toda a minha calma e tranquilidade (LIMA TRINDADE, 2011, p. 404).

Como um parrudo, James realça o pano de fundo em que se desenrola a trama da revelação de um amor que não veio. Ele remete ao modo como o narrador acompanha os aspectos descritos por uma imaginação fértil. Caso este falasse, o ato verbal projetado o lançaria para a iminência do ato sexual. O que descreve com a potência do olho, o baixinho arábe, o sujeito fortinho, como ele, enuncia a força da narrativa, o modo como diz de si, do sujeito que narra, a forma como dirige a narração. Há uma experiência de liberdade, 
justamente por ser urso, no instante em que o relatar surge livremente, sem controle, sem disciplina, enunciando o corpo nu. Por isso, o parrudo é mais do que um significado que atrai e retrai, mas um devir, que reterritorializa a entrega de falar de si, de tudo que colhe e ali vivencia, dizendo algo dele mesmo:

Depois, diria ao meu homem árabe que foi tudo muito mais do que uma boa foda. Ele juraria um amor misturado a choro e bebedeira. Eu acreditaria. Eu quero acreditar. Dividiriamos nossas horas entre filmes em preto e branco e beijos intermináveis. Seria este o cenário. O amor, novamente um clichê. Transformariamos nossas vidas num roteiro ruim (LIMA TRINDADE, 2011, p. 405).

Como na tela do cinema, o protagonista reelabora os códigos, cria uma linguagem sobre a qual constrói a imagem do desconhecido, portando-se como se nunca tivesse existido. O silêncio criado na escrita deduz o mesmo silêncio com o qual James se resigna a não gesticular. A imagem mostra um sujeito absorto do espaço, do acontecimento inesperado:

Estaremos no Caneca de Prata e o calor agitará o ar que espessas nuvens se formem, o vento irrompa sem aviso e grossas gotas de chuva desabem com virulência. É a mesma tempestade que me fez, me faz, aqui, no Caneca de Prata, chamar o garçom e 
pagar a conta, deixando-o ali, sentado no balcão. Tão distante e inalcançável como é belo o azul (LIMA TRINDADE, 2011, p. 405).

Portanto, a obra de Lima Trindade reporta a vivência de um desejo homoerótico que é contado como se fosse a primeira vez, dada a imagem de si a vir por instantes, sem cortar o tesão de olhar o paquera, sem cortar o efeito da ação. Como atuam, como falam e protagonizam os ursos, são questões que a narrativa importa do real, podendo visar ao que é narrado, sua única maneira de condensar os atos de si na imediatez do vivido. São essas as imagens que também a narrativa da escritora Állex Leilla incorpora, com todos os seus predecessores, pois não se trata de expor a si na linha do tempo remediado, e sim de recortar a ação de contar com vistas a repor outros lugares de expressão de outras identidades e que lhe serve de escritura. Assim, as subjetividades homoeróticas, nas obras de Állex Leilla e de Lima Trindade, mais do que revelar a si próprias, são portadas na decorrência de quem e como se enunciam e isso vale mais do que se fala. 


\section{REFERÊNCIAS}

BHABHA, Homi K. O local da cultura. Tradução de Myriam Ávila, Eliana Lourenço de Lima Reis e Gláucia Renata Gonçalves. Belo Horizonte: EDUFMG, 2001.

BAUMAN, Zygmunt. Amor líquido: sobre a fragilidade dos laços humanos. Tradução de Carlos Alberto Medeiros. Rio de Janeiro: Jorge Zahar, 2004.

BUTLER, Judith. Corpos que pesam: sobre os limites discursivos do "sexo". In: LOURO, Guacira Lopes (Org.). O corpo educado: pedagogias da sexualidade. Tradução de Tomaz Tadeu da Silva. Belo Horizonte: Autêntica, 2000.

CAMARGO, Flávio Pereira. Caio Fernando Abreu: um gaúcho além fronteiras. In: SILVA, Antonio de Pádua Dias da (Org.). Literatura contemporânea e homoafetividade. João Pessoa: Editora da UEPB; Realize Editora, 2011.

GIDDENS, Anthony. A transformação da intimidade: sexualidade, amor e erotismo nas sociedades modernas. Tradução de Magda Lopes. São Paulo: EDUNESP, 2003.

GARCIA, Wilton. O corpo espetacularizado. In: LYRA, Bernadette; GARCIA, Wilton. Corpo e cultura. São Paulo: Xamã: ECA-USP, 2001. p. 87-95. 
INÁCIO, Emerson da Cruz. Para uma estética pederasta. In: COSTA, Horácio et al. (Org.). Retratos do Brasil homossexual: fronteiras, subjetividades e desejos. São Paulo: Editora da Universidade de São Paulo; Imprensa Oficial, 2010.

LEILLA, Állex. Henrique. Salvador: Dominio Público, 2001.

ROJAS, Enrique. O homem moderno. São Paulo: Mandarim, 1996.

SENNETT, Richard. Carne e pedra: o corpo e a cidade na civilização ocidental. Tradução de Marcos Aarão Reis. Rio de Janeiro: Record, 2003.

SIMMEL, Georg. A metrópole e a vida mental. Tradução Sérgio Marques dos Reis. In: VELHO, Otavio Guilherme (Org.). O fenômeno urbano. Rio de Janeiro: Zahar, 1967. p. 11-25.

SCOTT, Joan. Prefácio a Gender and Politics of History. Cadernos Pagu. Campinas, v. 3, p. 11-27, 1994.

TRINDADE, Lima. Corações blues e serpentinas. São Paulo: Arte Pau Brasil, 2007.

TRINDADE, Lima. Eu, James Gandolfini (ou Jukebox). In: Nelson Oliveira de Geração Zero Zero: Fricções em Rede. Rio de Janeiro: Lỉngua Geral, 2011. 